\title{
Electron Microscopic Analysis of Stem Cells in Human Prostate Cancer, Including Inverted Capsule Embedding Methods for Archival Sections and Falcon Films for Prostate Cancer Cell Lines
}

\author{
AKHOURI A. SINHA ${ }^{1,2,3}$ \\ ${ }^{1}$ Research Service, Minneapolis Veterans Affairs Healthcare System, Minneapolis, MN, U.S.A.; \\ ${ }^{2}$ Department of Genetics, Cell Biology and Development, University of Minnesota, Minneapolis, MN, U.S.A.; \\ ${ }^{3}$ Masonic Cancer Center, University of Minnesota, Minneapolis, MN, U.S.A.
}

\begin{abstract}
Background/Aim: Identification of prostatic stem cells in primary prostate tissue sections, organ cultures of prostate and cell lines requires a range of techniques that allows characterization of stem cells for their potential use in the treatment of patients. Isolated cells usually round-up and develop changes in shape, size and cellular characteristics. The aim of this study was to provide a range of methods for identifying prostatic stem cells and characterizing them with regard to ultrastructure, nuclear morphology, cytoplasmic organelles, and/or expression stem cell marker CD133. Materials and Methods: Prostate biopsy and prostatectomy specimens were used for studying prostatic stem cells and their known marker CD133 in tissue sections by light and/or electron microscopy. Inverted capsule embedding was used to study archival metastatic prostate in pelvic nodes and Dul45 cell line in a monolayer culture. Results: Staining for CD133 positively identified stem cells that were found in benign prostatic hyperplasia, benign prostate, and prostate cancer cells. Paraffin embedded sections showed a single type of stem cells, whereas methylene blue-stained Epon sections showed both light and dark stem cells. Electron microscopy showed that both basal and stem cells were closely associated with the basement membrane (basal lamina). Stem cells had smooth plasma and nuclear membranes, a prominent nucleolus, small mitochondria, and few ribosomes. Du145 cells were separated
\end{abstract}

Correspondence to: Akhouri A. Sinha, Ph.D., VAMC Research Service (151), Building 70, One Veterans Drive, Minneapolis, MN 55417, U.S.A. Tel: +1 6127244871, Fax: +1 6127252093, e-mail: sinha001@umn.edu; Akhouri.Sinha@VA.gov

Key Words: Ultrastructure of stem cells, small mitochondria, localization of CD133, acinar cells, desmosomes and/or tight junctions, inverted capsule embedding methods, metastatic cancer, Falcon films, ultrastructure of Du145 cells. by intercellular spaces in monolayer culture. Conclusion: The inverted capsule embedding method allowed the study of metastasized prostate cancer in pelvic lymph nodes. Our approach enabled the assessment of stem cells in tissue sections by light and electron microscopy.

Stem cells are identified by staining for CD133 marker (1). Stem and basal cells are undifferentiated or poorly differentiated cells in the basal compartment whereas columnar/cuboidal and neuroendocrine cells are differentiated cells in the luminal compartment (2). Both stem and basal cells are closely associated with the basement membrane (1, 3-6). Cancer stem and normal stem cells often share molecular mechanisms and functional capabilities (7). Some basal cells have stem cell characteristics (8-11). Stem cells have an extensive capacity for self-renewal (12-14). The human prostate contains about $1 \%$ stem cells in benign (normal prostate), benign prostatic hyperplasia (BPH) and adenocarcinoma of the prostate $(11,15)$.

Identification of a small number of stem cells in tissue sections requires several approaches, including electron microscopy, immunostaining for the stem cell marker CD133 and/or other markers, such as alpha- $1 \mathrm{~B}_{2}$-integrin $(2,10,15$ 17). CD133 has been used to identify cancer stem cells in prostate and many other solid cancers (17). Any single approach has certain limitations, therefore, multiple approaches are required, especially for isolated stem cells in culture and tissue sections.

Human prostate cancer (PC) is a genetically, morphologically and pathologically heterogeneous tumor, and PC complexity is further increased by its regulation by a variety of steroid hormones (namely, testosterone, estrogen, progesterone) (2). Stem cells are independent of steroid hormones (18). Smith et al. have concluded that normal prostate and cancer stem cells have similar characteristics (7). Various mutations occur in stem cells imparting their selfrenewal properties $(13,18,19)$. Basal and stem cells in the 
basal compartment do not degenerate following androgen deprivation therapy (ADT) in human prostate or after castration in mice $(2,6)$. Stem cells are immune to androgen-based therapies $(20,21)$ and other therapies (17). In castrated mice, testosterone treatment triggers proliferation of stem cells followed by their differentiation into columnar/cuboidal cells (22). In contrast, luminal (columnar/cuboidal) cell degenerate following $\mathrm{ADT}$ in human prostate and some stem cells differentiate in human prostate following testosterone treatment $(2,6)$. The presence of androgen and estrogen receptors in some untreated and DES (diethylstilbestrol)-treated stem cells indicates that they are destined to differentiate into secretory cells. Some stem cells do not develop receptors and remain as stem cells $(2,23)$. We hypothesized that characterization of stem cells by ultrastructure, nuclear morphology, cytoplasmic organelles, and stem cell marker CD133, including utilization of inverted capsule embedding methods and growing cell lines on Falcon films may provide a range of criteria to identify stem cells in tissue sections, as well as when cells are isolated from prostate cancer sections.

\section{Materials and Methods}

Inverted capsule embedding method. We modified the inverted capsule embedding method used by others (23-25). Briefly, we utilized archival prostate tissue sections that were used in diagnosis of cancer. This involved deparaffinization of sections in xylene and processing them via graded ethanol to water and re-fixation in a combination of buffered $2 \%$ paraformaldehyde and $3 \%$ glutaraldehyde in $0.1 \mathrm{M}$ phosphate buffer at $\mathrm{pH} 7.3$ for $2 \mathrm{~h}$, as previously described $(26,27)$. Thick sections were washed in phosphate buffered saline (PBS) (4 changes), dehydrated in graded ethanol and absolute alcohol (26). Gelatin capsules were filled to the brim with Epon 812 and capsules were inverted on to the slides containing tissue sections and allowed to polymerize for 2 days at $60^{\circ} \mathrm{C}$. Slides were air cooled to room temperature and capsules were lifted from the slide that contained embedded areas (Figure 1b). Capsules containing appropriate areas were sliced to create thick sections (1-2 $(\mu \mathrm{m})$ for light microscopy and thin sections (about 400-500 angstrom) for electron microscopy. Prostate cancer and metastasized PC to the pelvic lymph node were fixed using the above approach. Paraffin sections were stained with-hematoxylin for light microscopy (Figure 1c). Thin sections were processed for electron microcopy as reported previously $(26,27)$.

Falcom film method. Certain prostate cell lines (such as LNCaP and Du-145) have played an important role in establishing tumor models for a variety of experiments. For example, Ohtsuki et al. have grown cells in Beem capsule for electron microscopy (28). Briefly, Du-145 prostate cells were grown as monolayer on Falcon 3006 film-lined dish (Becton Dickinson Labware Oxnard, CA, USA), fixed in 3\% buffered glutaraldehyde, washed in PBS, post-fixed with 1 to $2 \%$ buffered osmium-tetroxide for 1-2 h, washed again and embedded in Epon. Thick and thin sections were made using Reichert -Jung microtome (C. Reichert, Wien, Austria) for transmission electron microscopy. Thin sections were stained with lead citrate and uranyl acetate (Polysciences, Inc, Warrington, PA, USA) $(26,27)$.
Former Veterans Affairs Medical Center (VAMC) urology surgeon, Dr. Clyde E. Blackard and his associates, selected patients for biopsy and/or radical prostatectomy. Patients were not treated with any hormone therapy or chemotherapy prior to biopsy and prostatectomy. Prostate specimens were submitted to the Pathology Service of Minneapolis VAMC. Specimens not used in diagnosis of PC were collected for research between 1972 and 1975, embedded in Epon and stored. Prostate samples were obtained following the approval of the institutional review board (IRB) guidelines in place at the Department of Veterans Affairs (VA) and the University of Minnesota. Prostatectomy and/or biopsy tissue samples were fixed for two h using the combination of $2 \%$ paraformaldehyde and/or 3\% glutaraldehyde in $0.1 \mathrm{M}$ phosphate buffer at $\mathrm{pH} 7.3(26,27)$. Briefly, prostate pieces were washed in buffer and post-fixed in $1 \%$ to $2 \%$ buffered osmium-tetroxide, washed again, dehydrated in graded ethanol, and embedded in Epon 812, as previously described. Areas of interest were sliced for thick and thin sections using a ReichertJung microtome. Thin sections (about 400 -500 angstrom) were mounted on copper grids, stained with a combination of lead citrate and uranyl acetate and examined with RCA EMU 3 or 4 electron microscopes, as detailed $(26,27,29)$. Sections were graded by Drs. Donald F. Gleason and Nancy A. Staley, former staff pathologists at the Minneapolis VAMC. In addition, paraffin sections stained with or without hematoxylin and eosin were obtained for further study. A total of 25 untreated cases included only $4 \mathrm{BPH}$. They were examined by light and electron microscopy. The age of untreated patients ranged from 58 to 79 years and the mean \pm standard error of the mean was $70.54 \pm 3.60$. Patients had PC with pathological grades III and IV tumors which are comparable to Gleason histological scores 6 to 10 (30). Clinical stages were B, C and D (31). Benign prostatic hyperplasia and cancer pieces were used for localization of CD133 as we have previously described (2).

\section{Results}

Micrograph shows cellular details and nuclear morphology of Du-145 cells and the intercellular spaces (Figure 1a). Areas of sections lifted with the inverted capsule embedding method and the areas not embedded in the capsules are shown in Figure 1b. Metastasized prostate cancer cells are illustrated in the pelvic lymph nodes, which also show numerous lymphatic cells (Figure 1c). CD133 positive stem cells were identified in paraffin sections of benign prostatic hyperplasia and benign prostate (Figure 2a). Paraffin embedded sections showed a single type of stem cells, whereas methylene blue stained Epon sections showed light and dark stained stem cells, as described earlier (32) (Figure $2 b$ and $c)$.

Dark cells stain for basic protein whereas light cells do not $(2,32)$. Light stained stem cells were near the basement membrane and had round to oval nucleus with nucleolus (Figure 2c). Dark stained stem cells were also near the basement membrane (Figure 2c). Electron microscopy showed that the basal cells were closely associated with the basement membrane (basal lamina) in benign prostate, BPH and PC (Figure 2c). Electron micrograph illustrates two electron lucent stem cells (or light stem cells) (Figure 2d). 

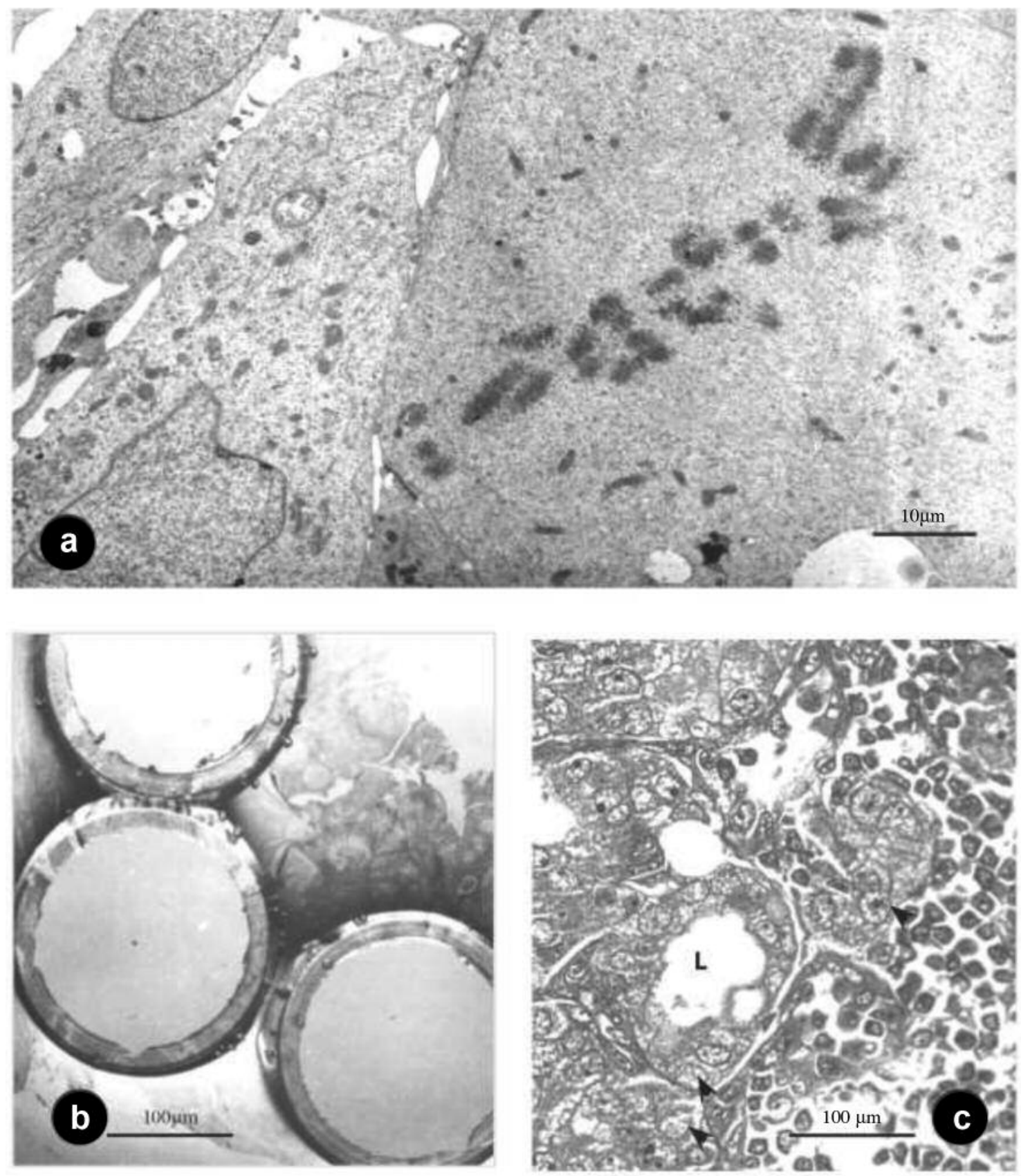

Figure 1. a. Electron micrograph of Du145 prostate cells shows nuclei, cytoplasmic organelles and interstitial spaces between cells. A dividing cell is showing aggregates of chromosomes. Bar shows magnification. b. Metastatic prostate in lymph node was embedded in Epon using inverted gelatin capsule method. Areas not embedded in capsules remain on the slide and those embedded in the capsules are removed. Bar shows magnification. c. Thick section illustrating metastatic prostatic glands among the nodal lymphocytes. Prostatic gland shows stem cell (arrows) and acinar lumen is shown by L. Bar shows magnification.

Stem cell cytoplasm has small mitochondria and few ribosomes. Golgi complex or secretory vacuoles and granules are found in differentiated cells (Figure 2d). Nuclei have smooth nuclear membranes in basal and stem cells, but columnar cells have either smooth and distorted nucleus and nuclear membrane (or nuclear plasticity) (Figure 2d). Micrographs also showed round to oval nucleus and nucleolus and relatively sparse cytoplasmic organelles in stem cells (Figure 3a). Columnar/cuboidal cells have numerous secretory granules, mitochondria and ribosomes. 

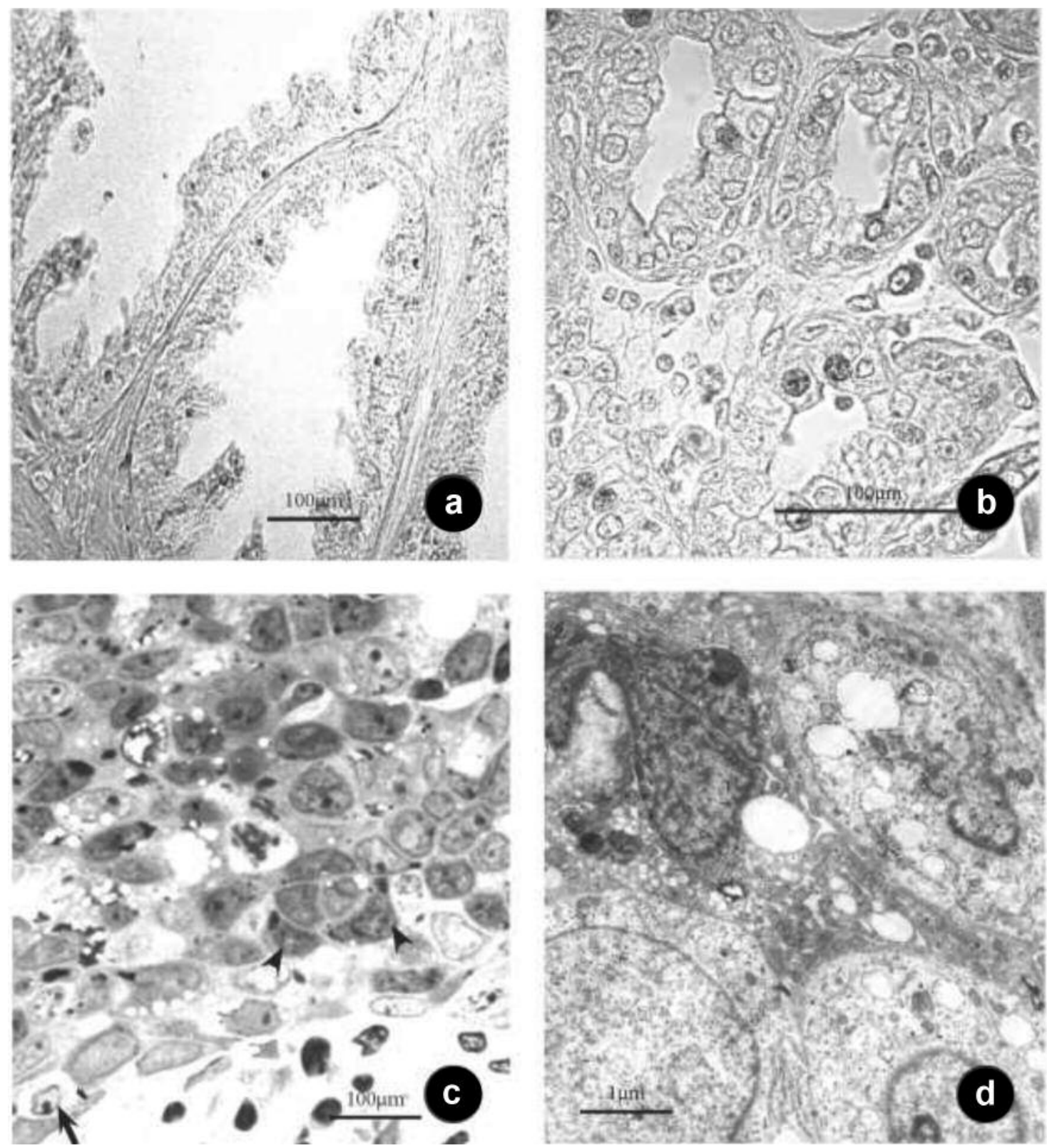

Figure 2. a. Stem cells in benign prostatic hyperplasia are shown by CD133 immunostaining. Glandular lumen and stroma do not show labelling indicating specificity of staining. Section was not counterstained (Prostate 473). Bar shows magnification. b. Localization of CD133 immunostaining in stem cells in PC. (Case \#391). Bar shows magnification. c. Methylene blue stained Epon section illustrates light stained stem cell (arrow) and dark stained stem cell (arrow heads). Label 'c' is in prostatic stroma. (Case \#40). Bar shows magnification. d. Electron micrograph illustrates two electron lucent stem cells (or light stem cells) also shown in figure (1c). Nuclei have smooth nuclear membranes, cytoplasmic organelles are sparse, and the cell is poorly differentiated. These cells are closely associated with each other and the adjacent secretory cells. Columnar cell nucleus is distorted (or nuclear plasticity) (Case \#40). Bar shows magnification.

In methylene blue-stained thick sections, stem cell nucleus was electron lucent or electron dense, which was comparable to light and dark cells in untreated cases reported previously (2). CD133 immunogold gold particles were identified in both light and dark stem cells. Thus, the basal compartment of the prostate contains basal and stem cells, which are undifferentiated cell types (Figure 3a). Columnar/cuboidal cells reached both the basement membrane and acinar lumen and had elongated nucleus along the baso-lateral axis (Figure 3a, b). Another stem cell 

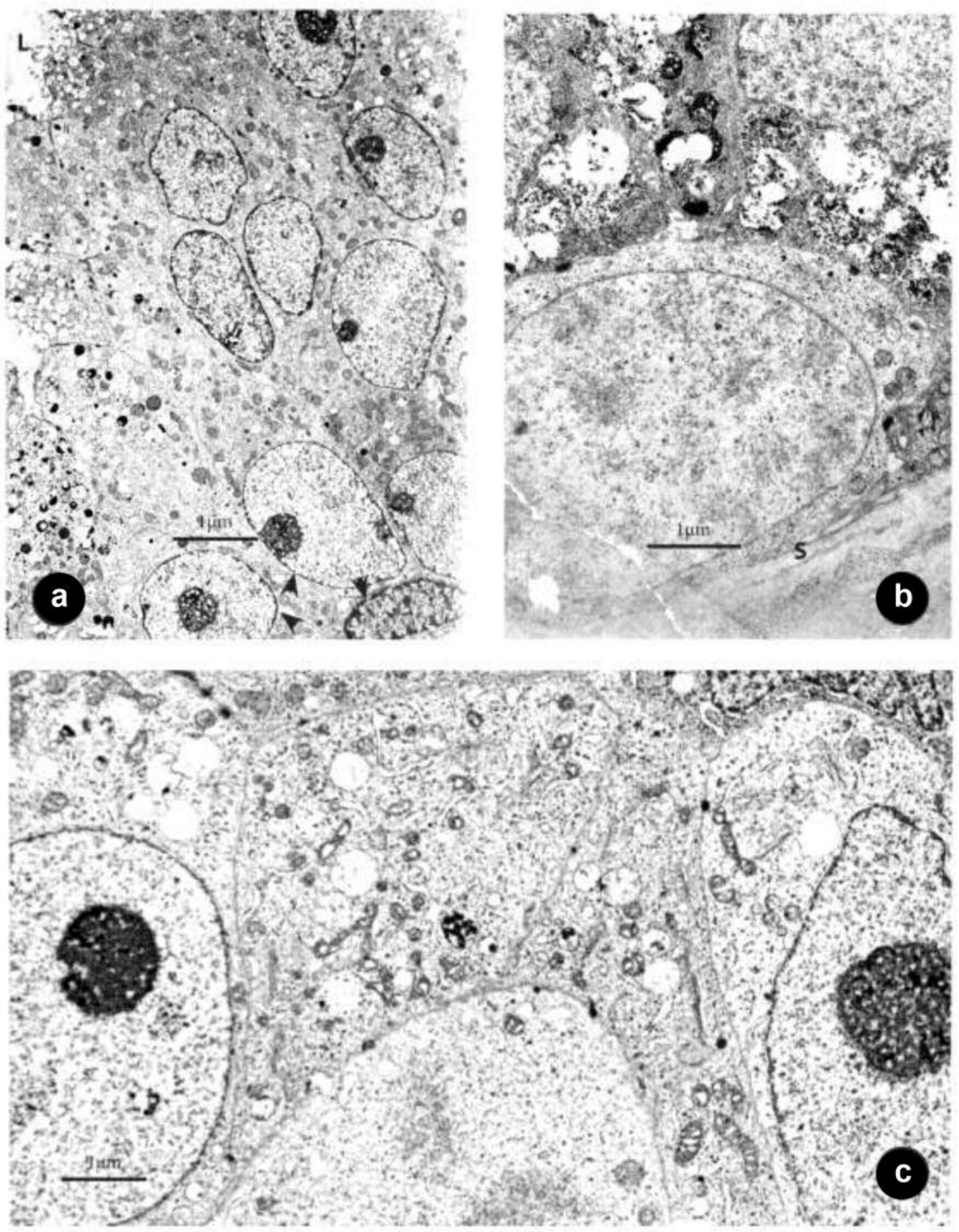

Figure 3. a. A low-power electron micrograph illustrates many acinar cells and acinar lumen $(L)$. A basal cell with dark stained nucleus is shown by an arrow head and adjacent two stem cells are shown by two arrow heads. Acinar cells show secretory granules and their nuclei. Stem cells have smooth nuclear membrane, and prominent nucleoli and small mitochondria. Cytoplasmic organelles in stem cells are sparse and poorly differentiated and are comparable to figure $2 d$. (Case \#110). Bar shows magnification. b. Another stem cell with nucleus illustrating aggregates of chromosomes within a smooth nuclear membrane and relatively sparse cytoplasmic organelles. The stem cell is closely associated with secretory cells showing secretory granules and vacuoles and a part of secretory cell nucleus. The labelling $(b)$ is in the stroma. (Case \#11). Bar shows magnification. c. Another stem cell illustrating aggregates of chromosomes within a smooth nuclear membrane and relatively sparse cytoplasmic organelles. This stem cell is closely associated with two other stem cells. Each stem cell has smooth nuclear membrane euchromatin and prominent nucleolus. Each stem cell is undifferentiated and has small mitochondria and ribosomes. (Case \#103). Bar shows magnification. 
shows aggregates of chromosomes within a smooth nuclear membrane and has relatively sparse cytoplasmic organelles. This stem cell is closely associated with two other stem cells (Figure 3c). Each stem cell is undifferentiated and has small mitochondria and ribosomes.

\section{Discussion}

Basal and stem cells are closely associated with each other and with acinar cells by desmosomes of tight junctions. In the past, lighter and darker stained basal cells had been observed by Kirchheim and Bacon (32) and subsequently by our group (27). We found that light and dark stained stem cells existed in untreated and DES-treated cases (27). Light stained stem cells and their progeny were androgen-sensitive, whereas dark stained stem cells were androgen-independent. Recently, we have shown that light stained cells have androgen receptors and dark stained cells have estrogen receptors (6). In the present study, basal and stem cells were readily identified by electron microscopy with and without staining for the stem cell marker, CD133 (2). In the past, studies have mostly focused on the cytological features of differentiated prostatic cells $(32,33)$. Electron microscopy allowed the assessment of stem cells by nuclear shape, distribution of heterochromatin and chromatin, cytoplasmic organelles, namely, small mitochondria and few ribosomes. Morphological features distinguish stem cells in tissue sections and metastatic prostate in the pelvic nodes. Staining for CD133 provided an additional method of identification of stem cells $(12,16,17,34)$.

Electron microscopy allowed the assessment of cellular details and nuclear morphology of Du145 cells and intercellular spaces between the cells. Collins et al. have used collagenase digestion of prostate tissue and BectonDickinson FACS-Scan method to study isolated stem cells $(15,16)$. Lang et al. have grown spheroids of prostate cell lines (PC-3) in Matrigel and analyzed their morphological features by light and electron microscopy (35). They have found differentiated luminal epithelial cells. The inverted capsule method allowed the analysis of metastatic prostate in pelvic lymph nodes. Metastatic prostate samples are difficult to obtain, but they can be readily processed for the inverted capsule embedding methods. This has enabled the assessment of interactions between metastatic cells and lymphatic cells in pelvic lymph nodes (36). In addition, the inverted capsule approach can be helpful in the study of metastases in archival solid organ cancers, namely, breast, colon, lung and brain cancers.

\section{Conflicts of Interest}

The Author has no conflict of interest to report regarding the publication of this article. The opinion expressed in this article is that of the author and not of the U.S. Government, Department of Veterans Affairs or the University of Minnesota.

\section{Acknowledgements}

This research was supported in part by the Research Service of the Minneapolis Veterans Affairs Medical Center by providing laboratory and other research facilities to AAS. The Author is grateful to Dr. Donald F. Gleason and Dr. Nancy A. Staley, former pathologists of the Minneapolis VA Medical Center, for grading prostate cancer sections. The Author is also grateful to Dr. Clyde E. Blackard and his associates for biopsy and prostatectomy specimens and Mr. Francis F. Pomroy, Jr., formerly at the Minneapolis VA Medical Center, for preparing sections. Many thanks go to James S. Hungaski and Mr. Jonathan Erickson and to the VA Medical Center Media Service for preparing the final plates of microphotographs; the staff of the Departments of Surgical Pathology, Library, and the Research Service. The Author thanks Ms. Martha K. Grace for helpful comments and critical proof reading of the manuscript.

\section{References}

1 De Marzo AM, Nelson WG, Meeker AK and Coffey DS: Stem cell features of benign and malignant prostate epithelial cells. J Urol 160: 2381-2392, 1998. PMID: 9817389.

2 Sinha AA and Wilson MJ: Identification of two types of stem cells in methylene blue-stained sections of untreated and diethlystilbestrol-treated human prostate cancer and their characterization by immunogold localization of CD133. Anticancer Res 38: 5725-5732, 2018. PMID: 30275193. DOI: 10.21873/anticanres. 12910

3 Leao R, Domingos C, Figueiredo A, Hamilton R, Tabori U and Castelo-Branco P: Cancer stem cells in prostate cancer: Implications for targeted therapy. Urol Int 99: 125-136, 2017. PMID: 28142149. DOI: 10.1159/000455160

4 Cabarcas SM, Mathews LA and Farrar WL: The cancer stem cell niche- there goes the neighborhood? Int J Cancer 129: 23152327, 2011. PMID: 21792897. DOI: 10.1002/ijc.263125

5 Miki J, Furusato B, Li H, Gu Y, Takahashi H, Egawa S, Sesterhaenn IA, Mcleod DG, Srivastava S and Rhim JS: Identification of putative stem cell markers, CD133 and CXCR4, in hTERT-immortalized primary nonmalignant and malignant tumor-derived human prostate epithelial cell lines and prostate cancer specimens. Cancer Res 67: 3153-3161, 2007. PMID: 17409422. DOI: 10.1158/0008-5472.CAN-06-4429

6 Sinha AA, Pomroy FE Jr. and Wilson MJ: Concurrent androgen and estrogen ablation and inhibition of steroid biosynthetic enzyme treatment for castration-resistant prostate cancer. Anticancer Res 36: 3847-3854, 2016. PMID: 27466486.

7 Smith BA, Sokolov A, Uzunangelov V, Berrtsch R, Newton Y, Graiim K, Mathis C, Cheng D, Stuart JM and Witte OW: A basal stem cells signature identifies aggresssive prostate cancer phenotypes. Proc Natl Acad Sci 112: E6544-E6552, 2015. PMID: 26460041. DOI: 10.1073/pnas.1518007112

8 Goldstein AS, Stoyanova T and Witte ON: Primitive origins of prostate cancer: In vivo evidence for prostate-regenerating cells and prostate cancer-initiating cells. Mol Oncol 4: 385-396, 2010. PMID: 20688584. DOI: 10.1016/j.molonc.2010.06.009

9 Lang SH, Frame FM and Collins AT: Prostate cancer stem cells. J Pathol 217: 299-306, 2009. PMID: 19040209. DOI: 10.1002/ path. 2478 
10 Kasper S: Exploring the origins of the normal prostate and prostate cancer stem cell. Stem Cell Rev 4: 193-201, 2008. PMID: 18563640. DOI: 10.1007/s12015-008-9033-1

11 Harris KS and Kerr BA: Prostate cancer stem cell markers drive progressison, therapeutic resistance and bone metastasis. Stem Cell Int 2017: 1-9, 2017. PMID: 28690641. DOI: 10.1155/ 2017/8629234

12 Collins AT and Maitland NJ: Prostate cancer stem cells. Eur J Cancer 42: 1213-1218, 2006. PMID: 16632344. DOI: 10.1016/ j.ejca.2006.01.037

13 Clarke M F, Dick JE, Dirks PB, Eaves CJ, Jamiesosn CHM, Jones LDL, Visvder J, Weissman IL and Wahl GM: Cancer stem cell-perspectives on current status and future direction. AACR workshop on cancer stem cells. Cancer Res 66: 9339-9344, 2006. PMID: 16990346. DOI: 10.1158/0008-5472.CAN-06-3126

14 Adamowicz J, Pakravan K, Bakhshinejad B, Drewa T and Babashah S: Prostate cancer stem cell from theory to practice. Scand J Urol 51: 95-106, 2017. PMID: 28635565. DOI: 10.1080/21681805.2017.1283360

15 Collins AT, Habib FK, Maitland NJ and Neal DE: Identification and isolation of human prostate epithelial stem cells based on alpha 2 beta-1-integrin expression. J Cell Sci 114: 3865-3872, 2001. PMID: 28635565. DOI: 10.1080/21681805.2017.1283360

16 Richardson GD, Robson C N, Lnag SH, Neal DE, Maitland NJ and Collins AT: CD133, a novel marker for human prostatic epithelial stem cells. J Cell Sci 117: 3539-3545, 2004. PMID: 15126633. DOI: $10.1242 /$ jcs.01074

17 Jaworska D, Krol W and Szliszka E: Prostate cancer stem cells: Research advances. Int J Mol Sci 16(11): 27433-27449, 2015. PMID: 2659389. DOI: 10.3390/ijms 161126036

18 Kelly K and Yin JJ: Prostate cancer and metastasis initiating stem cells. Cell Res 18(5): 528-537, 2008. PMID: 18414448. DOI: $10.1038 /$ cr.2008.50

19 Smith CV, Bauer JJ, Connelly RR, Seay T, Kane C, Foley J, Thrasher JB, Kusuda L and Moul JW: Prostate cancer in men age 50 years or younger: A review of the department of defense center for prostate disease research multicenter prostate cancer data base. J Urol 164: 1964-1967, 2000. PMID:11061892.

20 Yun EJ, Zhou J, Lin CJ, Hernandez E, Fazil Gleave M and Hsieh JT: Targeting cancer stem cells in castration-resistant prostate Cancer. Clin Cancer Res 22: 1-23, 2016. PMID: 27997863. DOI: 10.1016/j.diabres.2016.11.012

21 Maitland NJ and Collins AT: Prostate cancer stem cells: A new target for therapy. J Clin Oncol 26: 2862-2870, 2008. PMID: 18539965. DOI: $10.1200 / \mathrm{JCO} .2007 .15 .1472$

22 Sinha AA and Bentley MD: The relationship of epithelial cell types in the ventral prostate glands of castrated mice treated with testosterone. Anat Rec 208: 533-544, 1984. PMID: 6731862. DOI: 10.1002/ar.1092080409

23 Hanson HH, Reilly JE, Lee R, Janssen WG and Phillips GR: Streamlined embedding of cell monolayers on gridded glass-bioitn imaging dishes for correlative light and electron microscopy. Micros Microanal 16: 747-754, 2010. PMID: 21961484.

24 Mironov AA and Beznoussenko GV: Correlative microscopy: A potent tool for the study of rare or unique cellular and tissue events. J Microsc 235: 308-321, 2009. PMID: 19754725. DOI: $10.1111 / \mathrm{j} .1365-2818.2009 .03222 . x$
25 Murray AB, Schulze H and Blauw E: In situ embedding of cell monolayers cultured on plastic surfaces for electron microscopy. Biotec Histochem 66: 269-272, 1991. PMID: 1790242.

26 Sinha AA, Blackard CE, Doe RP and Seal US: The in vitro localization of $\mathrm{H} 3$ estrodial in human prostatic carcinoma: An electron microscopic autoradogaphic study. Cancer 31: 682-688, 1973. PMID: 4693598.

27 Sinha AA, Blackard CE and Seal US: A critical analysis of tumor morphology and hormone treatments in the untreated and estrogen-treated responsive and refractory human prostatic carcinoma. Cancer 40(6): 2836-2850, 1977. PMID: 201356.

28 Ohtsuki Y, Dmochwski L, Seman G and Brown JM: In situ embedding method for cells grown in beem capsules for immunoelectron microscopic studies of oncoRNAviruses. J Histochem Cytochem 26: 149-152, 1978. PMID: 203626. DOI: 10.1177/26.2.203626

29 Sinha AA, Wilson MJ and Gleason DF: Immunoelectron microscopic localization of prostatic-specific antigen in human prostate by the protein A-gold complex. Cancer 60(6): 12881293, 1987. PMID: 2441840.

30 Gleason DF and VACURG: Histologic grading and clinical staging of prostatic carcinoma. In: Urologic pathology: The prostate. Tannenbaum M (ed.). Lea \& Febiger: Philadelphia, PA, pp. 171-213, 1977.

31 Ellis WJ and Lange PH: Prostate cancer. Endocrinol Metab Clin North Am 23(4): 809-824, 1994. PMID: 7705321.

32 Kirchheim D and Bacon RL: Ultrastructural studies of carcinoma of the human prostate gland. Invest. Urol 6: 611-630, 1969. PMID: 4181513.

33 Brandes D: The fine structure and histochemistry of prostate glands in relation to sex hormones. Int Rev Cytol 20: 207-276, 1966. PMID: 5337300.

34 Collins AT, Barry, Hyde C, Stower MJ and Maitland NJ: Prospetive identification of tumorigenic prostate cancer stem cells. Cancer Res 65: 10946-10951, 2005. DOI: 1158/0008-5472 CANO 6-2018

35 Lang SH, Sharrard RM, Stark M, Villette JM and Maitland NJ: Prostate epithelisl cell lines form spheroids with evidence of glandular differentiation in three-dimensional matrigel cultures. Brit J Cancer 85: 590-599, 2001. PMID: 11506501. DOI: 10.1054/bjoc. 2001.1967

36 Sinha AA, Quast BJ, Wilson MJ, Fernandes ET, Reddy PK, Ewing SL and Gleason DF: Prediction of pelvic lymph node metastasis by the ratio of cathepsin B to stefin A in human prostate cancer. Cancer 94: 3141-3149, 2002. PMID: 12115346. DOI: $10.1002 /$ cncr.10604
Received February 15, 2019

Revised May 20, 2019

Accepted May 31, 2019 